\title{
A Lens to Understand Sanitation Workers and their Health Status in India
}

\author{
Rejesh Bose Kannolath* \\ Consultant, Health Portfolio, Tata Trusts UPHC Project PMU, Civil Lines, Nagpur, Maharashtra, INDIA.
}

It is estimated that there is around 5 million in India are employed as sanitation workers. Among them two millions are working under "High Risk" conditions. Despite of rapid growth in urbanisation and technology the working condition of these sanitation workers have remain unchanged since independence. Another inevitable concern needs to be understood while we study about sanitation workers is that it is also deeply rooted in Indian Caste system which assigns duties of sweeping, cleaning toilets, Manual scavenging to individuals from lowest sub castes of Dalit community.

A sanitation worker's job is very much conceived as a job which falls under the lowest class of job when it comes to categorisation of jobs, but on reality check, it is understood that without them communities and societies can't succeed and sustain. They forms the backbone of the civic cleaning system of any society and they performs valuable services to the society and state by collecting garbage and removing it to proper disposal areas.

While talking about sanitation workers it is also necessary to understand about different types of sanitation workers. Manual scavengers and safai karmacharis are of two major type of sanitation workers, Among them Manual scavengers are individuals employed by a public body or private body or an Individual for manually cleaning, carrying, disposing or handling in any manner, human excreta from dry latrines and sewers. Currently employment of manual scavenging is prohibited by Manual Scavengers and their Rehabilitation Act, 2013. But several cases of such death and practices are still reported across the country. ${ }^{[1]}$ Whereas safai karmacharis are sweepers or cleaning workers in municipalities, government offices or private offices. They may be directly employed or contractually employed by these bodies. They may be also involved in collection and disposals of garbage. But it is very important to be understood that Safai karmacharis are not Manual scavengers. ${ }^{[2]}$

In India we have approximate 5 million sanitation workers according to the latest data. ${ }^{[3]}$ Another study in 2008 says that there are 1.2 million of sanitation workers are employed across the nation. ${ }^{[4]}$ It is also a matter of concern that there is no official data available regarding the number of sanitation workers in the country.

In a developing economy, like India, due to its resource constraint, most of our cleaning process in urban localities remains manual. With improper segregation of waste materials at the source and all types of garbage being disposed on the streets, these workers are exposed to dirt, infective organisms and other hazardous materials like chemicals, animal excreta and sharp objects. As a result of this, they suffer from skin diseases, respiratory and gastrointestinal problems, eye and ear infections and accidental injuries. Published studies relating to the morbidities of sanitation workers are very few. Scarcity of health data in these workers is a cause of great concern.

A study in Toronto Canada in 1988 assessed the health status of a group of sewage workers in. Investigations of 50 randomly selected workers revealed that many workers reported influenza - like symptoms, cough, sputum production, wheezing, sore throat and skin complaints. ${ }^{[5]}$ A Lancet study identified that sewage Workers were having decreased lung functions. ${ }^{[6]}$ Watt et al. (1997) investigated 26 sewer men involved in an episode of toxic gas exposure by clinical follow-up, lung function test and measurement of pituitary function; 14 of them developed acute symptoms including sore throat, cough, chest tightness, breathlessness, thirst, sweating and irritability. ${ }^{\left[{ }^{[7]}\right.}$

In Indian context there were different studies on sanitation workers. One of the study on morbidity profile of sewage workers in Mumbai City found that a large proportion of workers suffered from work related symptomatic morbidities mainly of eye, respiratory, musculoskeletal system, gastrointestinal and skin. ${ }^{[8]}$

Another study in Chandrapur showed that, sanitation workers were exposed to a number of environmental and occupational hazards leading to musculoskeletal disorders (85\%), exposure to harmful gases $(65 \%)$, respiratory problems $(45 \%)$, headache $(40 \%)$, dermatological problem $(35 \%)$, gastrointestinal $(10 \%)$ and leptospirosis $(10 \%)$ during work. It was also observed that the sanitation workers were suffering from cough and cold $(90 \%)$, skin problems $(50 \%)$, allergies $(15 \%)$, malaria and typhoid $(15 \%)$, bronchitis lung and asthmatic problems $(10 \%)$ and hearing disorder $(5 \%)$ etc. ${ }^{[9]}$

A study in urban settings of Thrissur Municipal Corporation in Kerala identified that $34.4 \%$ workers presented with one acute illness and only $79.2 \%$ soughed medical help. $43.26 \%$ had chronic morbidities and $83.86 \%$ opted modern medicine. $53.9 \%$ of the workers were provided with personal protective equipment's and regular use was seen in $18 \%{ }^{\left[{ }^{[10]}\right.} \mathrm{A}$ study in same context in another southern state Karnataka noticed that among sanitation workers Injuries and chest pain were the most commonly reported illnesses

Most workers continued to work without appropriate treatment as they ignored their illness and did not want to miss their wages or lose their job. Self-medication was common. Intake of alcohol was prevalent to cope with the inhuman task of cleaning filthy sewage. ${ }^{[11]}$

A study on sanitation workers in Tiruchirappalli says that among sanitation workers $70 \%$ had several health issues such as gastrointestinal diseases, orthopaedic, skin related issues, asthma. $70 \%$ reported that they were stigmatized by the society. ${ }^{[12]}$ In a study conducted by Sudhir Naik et al. a total of 87 workers were screened, only 1 out of 87 workers used gloves while working and none of the 87 workers used masks or properly covered footwear like boots during the work hours. ${ }^{[13]}$

As all these recent studies in different contexts implies the need of more studies regarding morbidity status of sanitation workers. The nation also needs some tremendous policy changes for upliftment of sanitation workers not mere political dramas for the media. 


\section{REFERENCES}

1. The Dark Underbelly of Sanitation Workers and the Baggage of Caste Available from: https://www.newsclick.in/dark-underbelly-sanitation-workersand-baggagecaste

2. Occupational Health Issues of sewage and sanitary workers. Workosh. 2015;10(2)

3. Understanding the Problems of India's Sanitation Workers. Available from: https:// thewire.in/labour/understanding-the-problems-of-indias-sanitation-workers

4. Tiwari R. Occupational health hazards in sewage and sanitary workers. Indian J Occupat Environ Med. 2008;12(3):112.

5. Nethercott J, Holness D. Health Status of a Group of Sewage Treatment Workers in Toronto, Canada. Am Industrial Hygiene Asso J. 1988;49(7):346-50.

6. Rylander R, Lundholm M. "Sewage Worker Syndrome”. Lancet. 1976;28(2):478-9.

7. Watt M, Watt S, Seaton A. Episode of toxic gas exposure in sewer workers. Occupat Environ Med. 1997;54(4):277-80
8. Purushottam AG, Abhiram MK, Radha YA. A study on Morbidity Profile of sewage Workers in Mumbai City. Int J Collaborative Res Internal Med Public Health. 2010;2(12);450-63.

9. Patil P, Kamble R. Occupational Health Hazards in Sanitary Workers of Chandrapur City, Central India. Intl J Environ. 2017;6(3):15-24.

10. Chellamma P, Sudhiraj S, Vijayayakumar A. Morbidity Profile of Sanitary Workers in Thrissur Corporation, Kerala. J Evolution Med Dent Sci. 2015;4(89):15468-9.

11. Rangamani S, Obalesha KB, Gaitonde R. Health issues of sanitation workers in a town in Karnataka: findings from a lay health-monitoring study. Natl Med $\mathrm{J}$ India. 2015;28(2):70-3.

12. Sophia NS, Pavithra S. A Study on Sanitation workers at Thiruchirapally. Int J Applied Res. 2017;3(4):168-70.

13. Nayak S, Shenoi S, Kaur G, Bisen N, Purkayastha A, Chalissery J. Dermatologic evaluation of street sanitation workers. Indian J Dermatology. 2013;58(3):246.

*Correspondence to: Rejesh Bose Kannolath,

Consultant, Tata Trusts-Model UPHC Project PMU, Civil Lines, Nagpur-440001, Maharashtra, INDIA. Phone no: +918828208065 Email: rejeshbose@gmail.com

Copyright: (C) the author(s),publisher and licensee Indian Academy of Pharmacists. This is an open-access article distributed under the terms of the Creative Commons Attribution Non-Commercial

License, which permits unrestricted non-commercial use, distribution, and reproduction in any medium, provided the original work is properly cited.

Cite this article as: Bose KR. A Lens to Understand Sanitation Workers and their Health Status in India. J Pharm Pract Community Med. 2019;5(2):36-7. 